\title{
Deposition of low temperature Si-based insulators by the electron cyclotron resonance plasma method
}

\author{
S. Garcia, J.M. Martin, I. Martil, M. Fernandez * , G. Gonzalez-Diaz \\ Dpto. Fisica Aplicada III, F. Fisicas, U. Complutense, Madrid 28040, Spain
}

\begin{abstract}
The influence of the gas flow ratio $(R)\left(\mathrm{O}_{2} / \mathrm{SiH}_{4}\right.$ and $\left.\mathrm{N}_{2} / \mathrm{SiH}_{4}\right)$ and the deposition temperature on the physical properties of $\mathrm{SiO}_{y}$ and $\mathrm{SiN}_{x}: \mathrm{H}$ thin films deposited by the ECR-CVD method is analyzed. Two deposition regimes limited by $R=1$, are found for SiO $y$ films. At $R<1$, films are very Si-rich in nature, with [O]/[Si] ratios as low as 0.55 . At $R>1$, the [O]/[Si] ratio varies between 1.69 and 1.88 and the full width at half maximum of the $\mathrm{Si}-\mathrm{O}$ stretching peak is almost kept constant at $90 \mathrm{~cm}^{-1}$. The effect of increasing substrate temperatures is mainly to promote a nearest stoichiometric character of the films. The two deposition regimes described agree with the optical diagnosis of the discharge, that present $\mathrm{Si}$ related species in those created at $R<1$, and $\mathrm{OH}_{\text {and }} \mathrm{O}_{2}^{+}$species in those created at $R>1$. A similar trend is observed for the deposition of $\mathrm{SiN}_{x}: \mathrm{H}$ films, for which the limiting gas flow ratio is also $R=1$. At $R<1$, the films are very Si-rich $(x \leq 0.38)$, meanwhile at $R>1$, the composition corresponds to near stoichiometric and N-rich films $(x=0.91-1.49)$. The main effect of the substrate temperature is to reduce the hydrogen content of the films. $\mathrm{Both} \mathrm{SiO}_{y}$ and $\mathrm{SiN}_{x}: \mathrm{H}_{\text {films }}$

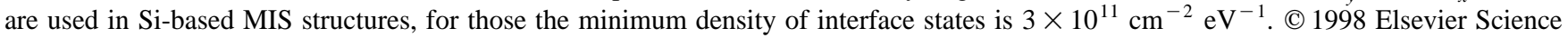
S.A.
\end{abstract}

Keywords: Deposition process; Electron cyclotron resonance plasma

\section{Introduction}

Thin films of $\mathrm{SiO}_{y}$ and $\mathrm{SiN}_{x}: \mathrm{H}$ deposited at low substrate temperatures $\left(\leq 200^{\circ} \mathrm{C}\right)$ have demonstrated their potential applications in device structures based on silicon and on III-V compound semiconductors [1]. In recent years, one of the most useful plasma methods used to obtain these films has been the electron cyclotron resonance plasma deposition method (ECR-CVD) [2,3]. The results published at this time using this method are mainly focused on near stoichiometric films. In this paper, we compare the deposition of $\mathrm{SiO}_{y}$ and $\mathrm{SiN}_{x}: \mathrm{H}$ films using the ECR-CVD method and a wide variety of deposition conditions which results in films with different stoichiometries.

\section{Experimental}

The deposition system consists of a commercial reactor divergent type, attached to a deposition chamber of our

\footnotetext{
" Corresponding author. Instituto de Ciencia de Materiales, Cantoblanco 28049, Madrid, Spain.
}

design. The gases used for the $\mathrm{SiO}_{y}$ deposition were $\mathrm{O}_{2}$ and $\mathrm{SiH}_{4}$. For the $\mathrm{SiN}_{x}: \mathrm{H}$ deposition, the $\mathrm{O}_{2}$ gas was substituted with $\mathrm{N}_{2}$. The gas flow ratios $\mathrm{O}_{2} / \mathrm{SiH}_{4}$ and $\mathrm{N}_{2} / \mathrm{SiH}_{4}(R)$ changed between 0.5 and 20 , and between 0.5 and 9 , respectively. The deposition temperature was varied between $50^{\circ} \mathrm{C}$ and $200^{\circ} \mathrm{C}$. Microwave power and deposition pressure were kept constant at $100 \mathrm{~W}$ and 2 mTorr, respectively. Auger Electron Spectroscopy was used to measure the $[\mathrm{O}] /[\mathrm{Si}]$ and $[\mathrm{N}] /[\mathrm{Si}]$ ratios in the $\mathrm{SiO}_{y}$ and $\mathrm{SiN}_{x}: \mathrm{H}$ films, respectively. Infrared absorption spectroscopy (FTIR) was used to study the bonding structure of both films and to measure the hydrogen content of the $\mathrm{SiN}_{x}: \mathrm{H}$ films [4]. In order to characterize the discharge, optical diagnosis spectroscopy was used. The spectra are recorded through a quartz window by using a monochromator (Jovin Ivon H25) operating in the 200-800 nm wavelength range, and they correspond to the whole downstream plasma volume.

\section{Deposition of $\mathrm{SiO}_{\mathrm{y}}$ films}

Fig. 1 shows two optical diagnosis spectra of the discharges created at different $\mathrm{O}_{2} / \mathrm{SiH}_{4}$ gas flow ratios, 


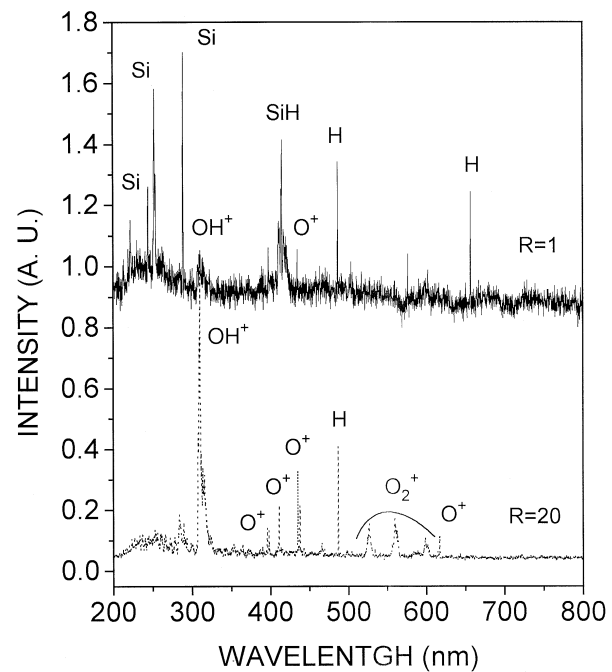

Fig. 1. Optical diagnosis spectra of the discharges created at $\mathrm{O}_{2} / \mathrm{SiH}_{4}$ gases flow ratio $R=1$ and $R=20$. The spectrum that corresponds to $R=1$ is shifted in the $y$ axis for clarity.

$R=1$ and $R=20$. For those created at $R=20$, the most intense peak corresponds to the molecular specie $\mathrm{OH}^{+}$, and the rest of the peaks are mainly related to the oxygen gas used in the discharge, such as different atomic species $\mathrm{O}^{+}$and the triplet peak corresponding to the $\mathrm{O}_{2}^{+}$molecule. The high efficiency and high ionization ratio of the ECR plasma method is demonstrated in the spectra as the $\mathrm{O}_{2}$ molecules appeared dissociated either as atomic oxygen $\mathrm{O}^{+}$or ionized as $\mathrm{O}_{2}^{+}$molecules. The $\mathrm{OH}^{+}$molecule observed also indicates a high efficiency for vapor phase reactions, and the most probable origin of this molecule are the reactions between atomic oxygen coming from the $\mathrm{O}_{2}$ molecules and $\mathrm{H}$ evolved from the decomposition of the $\mathrm{SiH}_{4}$ molecules in $\mathrm{SiH}_{n}$ radicals $(n=0-3)$ and $\mathrm{H}$ atoms. It is difficult to relate this molecule to other sources, such as the presence of $\mathrm{H}_{2} \mathrm{O}$ in the deposition chamber due to a poor base pressure, as it has not been observed in $\mathrm{N}_{2} / \mathrm{SiH}_{4}$ discharges formed at similar conditions. Different species are observed in the spectra of the discharge created at $R=1$, since the peaks are mainly related to $\mathrm{Si}$. In this case, the $\mathrm{OH}^{+}$molecule is hardly observed in the spectra, while the most intense peak corresponds to atomic $\mathrm{Si}$ according to the high $\mathrm{SiH}_{4}$ flow of the discharges generated at low $R$ values. Peaks corresponding to the $\mathrm{SiH}$ molecule and atomic $\mathrm{H}$ are also observed, which confirms the decomposition of the $\mathrm{SiH}_{4}$ molecules in $\mathrm{SiH}_{n}$ radicals and $\mathrm{H}$ atoms.

Fig. 2a presents the $[\mathrm{O}] /[\mathrm{Si}]$ ratio of the $\mathrm{SiO}_{y}$ films as a function of the gas flow ratio for those films deposited at $50^{\circ} \mathrm{C}$, and includes some results obtained at $200^{\circ} \mathrm{C}$. Two different deposition regimes (separated by $R=1$ ) can be concluded for films deposited at $50^{\circ} \mathrm{C}$. Those films deposited at $R<1$ are silicon-rich, with $[\mathrm{O}] /[\mathrm{Si}]$ ratios as low as 0.55 . At $R=1$, the $[\mathrm{O}] /[\mathrm{Si}]$ ratio suddenly increases, obtaining a plateau of about 1.8 in this ratio for higher $R$ values. Fig. $2 \mathrm{~b}$ presents the full width at half maximum (FWHM) of the $\mathrm{Si}-\mathrm{O}$ stretching vibration mode as a function of the gas flow ratio for films deposited at three different temperatures. For those deposited at $50^{\circ} \mathrm{C}$, the two different deposition regimes are also observed in this figure. The high FWHM value of films deposited at $R<1$ is explained as a dispersion of the bonding angles of the system $\mathrm{Si}-\mathrm{O}-\mathrm{Si}$, caused by induction effects of the $\mathrm{Si}$ neighbors on the system [5]. For $R>1$, the FWHM is nearly constant at a value $\left(\sim 90 \mathrm{~cm}^{-1}\right)$ close to that corresponding to thermal $\mathrm{SiO}_{2}$ films.

The two deposition regimes deduced from the film characteristics are well related to the radical species observed in the optical diagnosis of the discharge. At $R \leq 1$, the plasma species are mainly related to silicon, and the absence of oxygen related species, caused by the low oxygen flow, results in silicon-rich films. At $R>1$, the oxygen flow is high enough to promote oxygen incorporation into the film, in agreement with the presence of oxygen-related species in the optical diagnosis spectra. The films deposited at $50^{\circ} \mathrm{C}$ and $R>1$ have similar properties to those reported in the literature for ECR-CVD $\mathrm{SiO}_{y}$ films deposited at different temperatures $\left(\leq 200^{\circ} \mathrm{C}\right)[6,7]$. However, there is no evidence in the literature of the two different deposition regimes observed in this study, probably because the different authors mainly focus on deposition conditions resulting in near stoichiometric films.

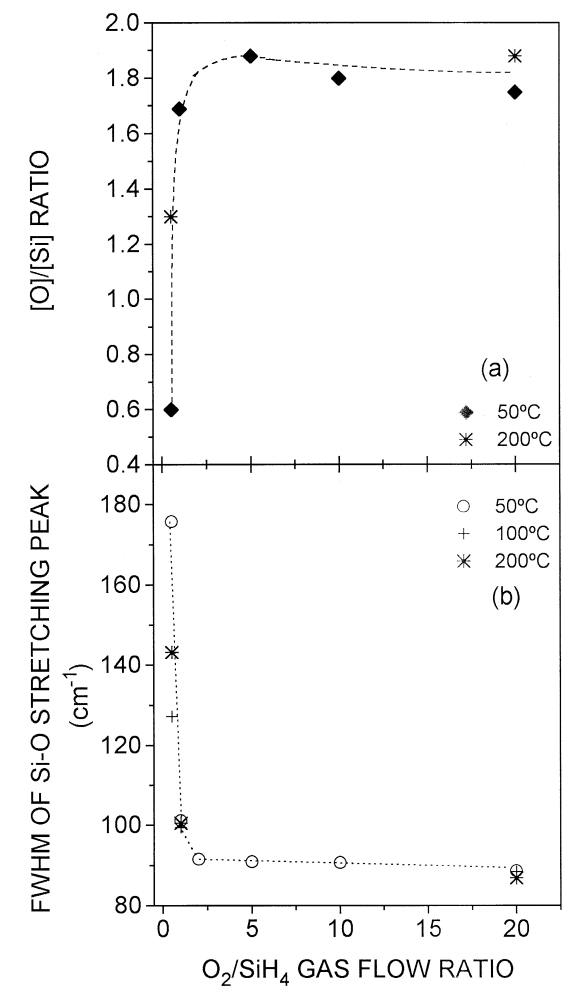

Fig. 2. (a) $[\mathrm{O}] /[\mathrm{Si}]$ ratio of the $\mathrm{SiO}_{y}$ films deposited at $50^{\circ} \mathrm{C}(\diamond)$ and $200^{\circ} \mathrm{C}\left({ }^{*}\right)$ as a function of the gases flow ratio $R$. (b) FWHM of the $\mathrm{Si}-\mathrm{O}$ stretching peak for the $\mathrm{SiO}_{y}$ films deposited at $50^{\circ} \mathrm{C}(\mathrm{O}), 100^{\circ} \mathrm{C}$ $(+)$ and $200^{\circ} \mathrm{C}\left({ }^{*}\right)$ as a function of the $\mathrm{O}_{2} / \mathrm{SiH}_{4}$ gases flow ratio. 
The effect of increasing deposition temperatures on the film characteristics can be observed in Fig. 2a,b, which include the data of films deposited at different temperatures. At $R>1$, the increase of the temperature up to $200^{\circ} \mathrm{C}$ has a small influence on the film characteristics. The FWHM of the Si-O stretching peak is not affected by this parameter, and the $[\mathrm{O}] /[\mathrm{Si}]$ ratio slightly increases when the temperature changes from $50^{\circ} \mathrm{C}$ to $200^{\circ} \mathrm{C}$. At $R<1$, the increase of temperature seems to activate the thermal reactions on the substrate, and to contribute with an additional energy to the reaction between species, as indicated by the increase of the $[\mathrm{O}] /[\mathrm{Si}]$ ratio and the clear decrease of the FWHM of the $\mathrm{Si}-\mathrm{O}$ stretching peak. Deposition temperatures higher than $200^{\circ} \mathrm{C}$ are not investigated in this work, since the main objective is to use the $\mathrm{SiO}_{y}$ and $\mathrm{SiN}_{x}: \mathrm{H}$ films in MIS structures based on InP.

\section{Deposition of $\mathrm{SiN}_{\mathrm{x}}: \mathrm{H}$ films}

Fig. 3 presents the $[\mathrm{N}] /[\mathrm{Si}]$ ratio for $\mathrm{SiN}_{x}: \mathrm{H}$ films deposited at different gas flow ratio $\mathrm{N}_{2} / \mathrm{SiH}_{4}$ and $200^{\circ} \mathrm{C}$. Previous studies not included in this work indicate that the deposition temperature has no influence on the $[\mathrm{N}] /[\mathrm{Si}]$ ratio of the films. The two deposition regimes observed for the $\mathrm{SiO}_{y}$ films deposited at $50^{\circ} \mathrm{C}$ are also observed for the $\mathrm{SiN}_{x}: \mathrm{H}$ films deposited at $200^{\circ} \mathrm{C}$. At this deposition temperature, the films obtained at $R<1$ are very silicon-rich films, while those obtained at higher $R$ values can be considered as near stoichiometric films $(x=0.91-1.41)$ and nitrogen-rich films $(x=1.46-1.49)$ [8,9]. Differences between the deposition characteristics of $\mathrm{SiO}_{y}$ and $\mathrm{SiN}_{x}: \mathrm{H}$ films are found at high $R$ values. In fact, $\mathrm{N}_{2} / \mathrm{SiH}_{4}$ ratios

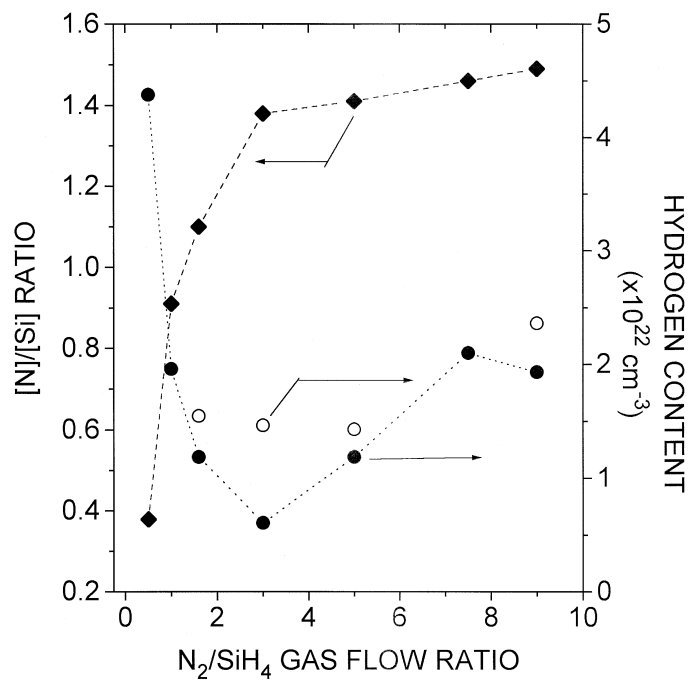

Fig. 3. $[\mathrm{N}] /[\mathrm{Si}]$ ratio $(\diamond)$ and hydrogen content for $\mathrm{SiN}_{x}: \mathrm{H}$ films deposited at $50^{\circ} \mathrm{C}(\mathrm{O})$ and $200^{\circ} \mathrm{C}(\mathbf{)})$ as a function of the $\mathrm{N}_{2} / \mathrm{SiH}_{4}$ ratio. The $[\mathrm{N}] /[\mathrm{Si}]$ ratio corresponds to films deposited at $200^{\circ} \mathrm{C}$.

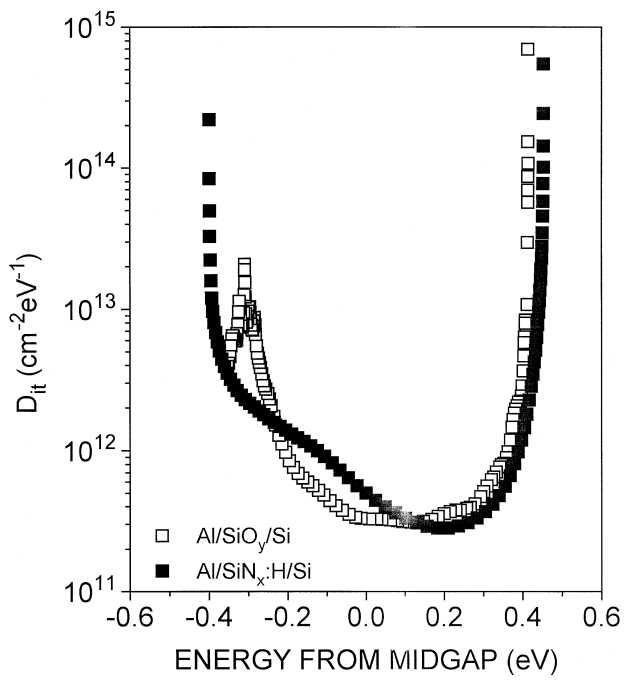

Fig. 4. Distribution of the density of interfacial states in the silicon gap energy for MIS structures fabricated on $\mathrm{Si}$ using as insulator $\mathrm{SiO}_{y}$ films ( $\square$ ) and $\mathrm{SiN}_{x}: \mathrm{H}$ films ( $\square$ ) deposited at $200^{\circ} \mathrm{C}$ and $R=20$ and $R=3$, respectively. The gap energy is measured from the midgap.

higher than 5 result in nitrogen-rich films, which indicates a high activation of the $\mathrm{N}_{2}$ gas in the discharge. On the contrary, as it has been described in previous paragraphs, the deposition of $\mathrm{SiO}_{y}$ films at similar $\mathrm{O}_{2} / \mathrm{SiH}_{4}$ ratios results in $[\mathrm{O}] /[\mathrm{Si}]$ values lower than $y=2$.

Fig. 3 includes the hydrogen content measured in the $\mathrm{SiN}_{x}: \mathrm{H}$ films deposited at $50^{\circ} \mathrm{C}$ and $200^{\circ} \mathrm{C}$ as a function of $R$. For all films considered, the hydrogen content decreases when the deposition temperature increases as is expected from previous results in the literature for $\mathrm{SiN}_{x}: \mathrm{H}$ plasma deposited films [10]. For both temperatures, the hydrogen content has a minimum value at $R=3-5$ which corresponds to near stoichiometric films $(x=1.38-1.41)$. The lowest $\mathrm{Si}-\mathrm{H}$ and $\mathrm{N}-\mathrm{H}$ bond densities are found at $R=3-$ 5 , which explains the minimum hydrogen content at this gas flow ratio $[11,12]$.

\section{MIS structures}

Both $\mathrm{SiO}_{y}$ and $\mathrm{SiN}_{x}: \mathrm{H}$ films have been used as insulators in silicon based MIS structures. Fig. 4 presents the density of interfacial states distribution as a function of the gap energy measured for MIS structures fabricated using both $\mathrm{SiO}_{y}$ and $\mathrm{SiN}_{x}: \mathrm{H}$ films. Both films are deposited at $200^{\circ} \mathrm{C}$ and at $R=20$ and $R=3$, respectively, which corresponds to the $[\mathrm{O}] /[\mathrm{Si}]$ and $[\mathrm{N}] /[\mathrm{Si}]$ ratios nearest to the stoichiometric value of all films considered. For $\mathrm{Al} / \mathrm{SiO}_{y} / \mathrm{Si}$ structures, the minimum $D_{\text {it }}$ value $(\sim 3.00 \times$ $\left.10^{11} \mathrm{~cm}^{2} \mathrm{eV}^{-1}\right)$ is higher than those reported in the literature for plasma deposited $\mathrm{SiO}_{y}$ films [13]. For $\mathrm{Al} / \mathrm{SiN}_{x}: \mathrm{H} / \mathrm{Si}$ structures, the $D_{\mathrm{it}}$ values are between the better ones reported in the literature [14], which shows the 
suitability of the $\mathrm{SiN}_{x}: \mathrm{H}$ films deposited by the ECR-CVD method to be used in silicon based device structures. Moreover, the $D_{\mathrm{it}}$ distribution for the $\mathrm{Al} / \mathrm{SiN}_{x}: \mathrm{H} / \mathrm{Si}$ structures is extended in almost the whole energy gap, which demonstrates the absence of traps that pinch off the Fermi level, and the quality of the interface $\mathrm{SiN}_{x}: \mathrm{H} / \mathrm{Si}$ obtained by the ECR-CVD method. The results of the application of $\mathrm{SiN}_{x}: \mathrm{H}$ films in $\mathrm{InP}$ based MIS structures will be presented in future works.

\section{Conclusions}

Two deposition regimes have been observed for $\mathrm{SiO}_{y}$ and $\mathrm{SiN}_{x}: \mathrm{H}$ films deposited by the ECR-CVD method, limited by the gas flow ratio $R=1$. Films deposited at $R<1$ are very silicon-rich, whereas the $[\mathrm{O}] /[\mathrm{Si}]$ and $[\mathrm{N}] /[\mathrm{Si}]$ ratio abruptly increase at higher $R$ values. Differences between the deposition mechanism of both type of films are observed at $R \geq 5$. At these gas flow ratios, the $\mathrm{SiN}_{x}: \mathrm{H}$ films obtained are nitrogen-rich, while the $[\mathrm{O}] /[\mathrm{Si}]$ ratio of the $\mathrm{SiO}_{y}$ films is lower than 2, which demonstrates a low activation of the $\mathrm{O}_{2}$ gas. The effect of increasing deposition temperatures is to increase the $[\mathrm{O}] /[\mathrm{Si}]$ ratio of the $\mathrm{SiO}_{y}$ films, and to reduce the hydrogen content of the
$\mathrm{SiN}_{x}: \mathrm{H}$ films. The application of both type of films in devices structures is demonstrated by the low density of interfacial states measured in silicon based MIS structures.

\section{References}

[1] Y. Ma, T. Yasuda, G. Lucovsky, Appl. Phys. Lett. 64 (1994) 2226.

[2] J.R. Flemish, R.L. Pfeffer, J. Appl. Phys. 74 (1993) 3277.

[3] D.E. Kotecki, J.D. Chapple-Sokol, J. Appl. Phys. 77 (1995) 1285.

[4] W.A. Lanford, M.J. Rand, J. Appl. Phys. 49 (1978) 2473.

[5] G. Lucovsky, J.T. Fitch, D.V. Tsu, S.S. Kim, J. Vac. Sci. Technol. A 7 (1989) 1136.

[6] T.V. Herak, T.T. Chau, D.J. Thomson, S.R. Mejia, D.A. Buchanan, K.C. Kao, J. Appl. Phys. 65 (1989) 2457.

[7] M.J. Hernandez, J. Garrido, J. Piqueras, J. Vac. Sci. Technol. B 12 (1994) 581.

[8] S. Hasegawa, M. Matuura, H. Anbutu, Y. Kurata, Phil. Mag. B 56 (1987) 633.

[9] A.D. Stewart, D.I. Jones, Phil. Mag. B 57 (1988) 431.

[10] W.A.P. Claassen, W.G.J.N. Valkenburg, F.H.P.M. Habraken, Y. Tamminga, J. Electrochem. Soc. 130 (1983) 2419.

[11] S. Garcia, J.M. Martin, M. Fernandez, I. Martil, G. Gonzalez-Diaz, Phil. Mag. B. 73 (1996) 487.

[12] S. Garcia, D. Bravo, M. Fernandez, I. Martil, F.J. Lopez, Appl. Phys. Lett. 67 (1995) 3263.

[13] T.T. Chau, S.R. Mejia, K.C. Kao, Electron. Lett. 25 (1989) 1088.

[14] S.V. Hattangady, G.G. Fountain, R.A. Rudder, R.J. Markunas, J. Vac. Sci. Technol. A 7 (1989) 570. 